\title{
Electronic Media to Enhance Electrical Engineering Education
}

\author{
Don Millard, Gerald Burnham \\ Rensselaer Polytechnic Institute/University of Texas-Dallas
}

\section{Motivation}

Electrical Engineering (EE) students play computer games watch television, surf the web, instant message and use search engines - all allowing them to switch content at will - rather than focusing on a singular offering. This results in a shortened attention span, lower tolerance for repetition and static media. This clearly challenges educators to provide information in more dynamic, compelling, and interactive ways. ${ }^{1}$

Simultaneously, our insatiable desire for more electronics functionality and higher performance computing - increases the demand for companies to hire students with advanced skills in science, math, engineering and technology. Electrical and Computer Engineering (ECE) degree programs are exhibiting large enrollments in engineering schools. According to John Wiley \& Sons, Inc., the circuit analysis, electronics, and signals \& systems market is estimated to involve more than 100,000 students in 2003-2004. This large population generates a tremendous need for interactive educational materials that are able to cover a broad spectrum of engineering concepts and applications. ECE degrees also open doors to other careers. Many EE graduates have moved into other professions such as medicine, law, and business where their engineering education has been a valuable asset.

As educators, we need to incorporate practical examples, engaging illustrative materials and interactive teaching methods that reach and motivate the diverse groups that are involved. Dynamic interactive electronic media facilitates this flexibility, allowing users to guide themselves through the materials according to their own level and interest. Furthermore, educators now have the potential to identify a student's learning style ${ }^{2,3}$ and conceptual problems, thus allowing them to deliver education in more effective ways using a combination of learning technologies, virtual simulations, visualizations, web-based experimentation, and collaborative technologies.

Today we depend on computers and the Internet to do our jobs, yet with all this available technology we have only begun to scratch the surface of how we may harness the microprocessor to improve education. ${ }^{4}$ Interactive "Studio" based instruction at Rensselaer has been successful in mathematics, science and electrical, computer and systems engineering courses ${ }^{5}$ - where computers are used to: help explain concepts with dynamic media; simulate design and performance; and process data from real or virtual experiments. In a typical two-hour class with a score of three to five different modes of orchestrated activity (e.g. lecture, problem solving, experiments, etc.), the challenge is to provide "adequate" time for each activity so that all students can benefit. Notwithstanding, there is a need to provide supplemental "if you have time" components (e.g. engaging interactive modules) so all students can maintain interest. ${ }^{6}$

The incorporation of animation, interactive simulation, video, and expert commentaries 
dramatically improves the impact of educational materials since the first-hand characteristics and constraints of the engineering environment are essential to understanding of the principles. ${ }^{7,8}$

Furthermore, educational multimedia can foster scaffolding of knowledge and improve retention since software restructuring permits the user to guide oneself through the materials at their own level and interest. ${ }^{9}$ Our objective was to develop, deploy, evaluate and disseminate interactive learning modules and educational technologies that address the above issues and attempt to improve electrical engineering education.

\section{Project Description}

Our goal was to improve electronics-related Studio education through the development and utilization of 24 interactive learning modules (ILMs - listed in Table 1) coupled with web-based educational information technologies. ${ }^{10}$

\begin{tabular}{|c|c|c|c|}
\hline & \multicolumn{3}{|c|}{$\begin{array}{c}\text { CCLI MODULES } \\
\text { http:/wWW.acodemu.pi.edu/projects/cdi }\end{array}$} \\
\hline & Circuits & Signals \& Systems & Communications \\
\hline $\begin{array}{l}2 . \\
3 . \\
4 . \\
5 .\end{array}$ & $\begin{array}{l}\text { Generic } \\
\text { Voltage } \\
\text { Divider } \\
\text { Filters } \\
\text { Introduction } \\
\text { Filters CAD } \\
\text { Band Pass } \\
\text { Filters } \\
\text { Phasors in } \\
\text { Circuit } \\
\text { Analysis } \\
\text { Circuit Solver } \\
\text { Caps and } \\
\text { Inductors } \\
2^{\text {nd }} \text { Order } \\
\text { Systems }\end{array}$ & $\begin{array}{l}\text { 9. Fourier } \\
\text { Transform } \\
\text { 10. Fourier Signal } \\
\text { Generator } \\
\text { 11. Wave } \\
\text { Chooser } \\
\text { 12. Convolution } \\
\text { 13. Time/Free/ } \\
\text { Laplace } \\
\text { Domains } \\
\text { 14. Op-Amps } \\
\text { CAD } \\
\text { 15. Learning } \\
\text { Styles Survey } \\
\text { 16. Amplitude } \\
\text { Modulation }\end{array}$ & $\begin{array}{l}\text { 17. A/D } \\
\text { Conversion } \\
\text { 18. Sampling } \\
\text { 19. Analog } \\
\text { Modulation } \\
\text { 20. Digital } \\
\text { Modulation } \\
\text { 21. Pulse } \\
\text { Modulation } \\
\text { 22. Freeuency } \\
\text { Division } \\
\text { Multiplexing } \\
\text { 23. TDM } \\
\text { 24. FDMA }\end{array}$ \\
\hline
\end{tabular}

Table 1

CCLI modules developed under project 
The Macromedia Director ${ }^{\mathrm{TM}}$ based materials engage the student in the learning process and present the content in a format that enhances the visualization of "big ideas" in electrical engineering. The technologies include: 1) a means to capture, review and process all user interactivity while accessing a learning module (Scribe); 2) an interactive, collaborative tool for exploration, design and testing across the Internet (WebTeam); and 3) access to instrumented experimentation via the Internet (LongLab). Twenty-four modules have been developed, and were specifically designed to maximize the potential for multiple use of the same content. For example, the capacitors and inductors materials can be used individually as a specific tutorial module (as depicted in figure 1) or together in a group, such as in the series \& parallel impedances module (as depicted in Figure 2).

interactive learning:

Inductors

Here we look at the relationship between voltage

and current for a current input that is a sine wave.

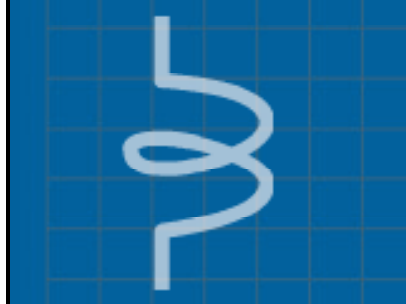

$0.588 \mathrm{~A}$
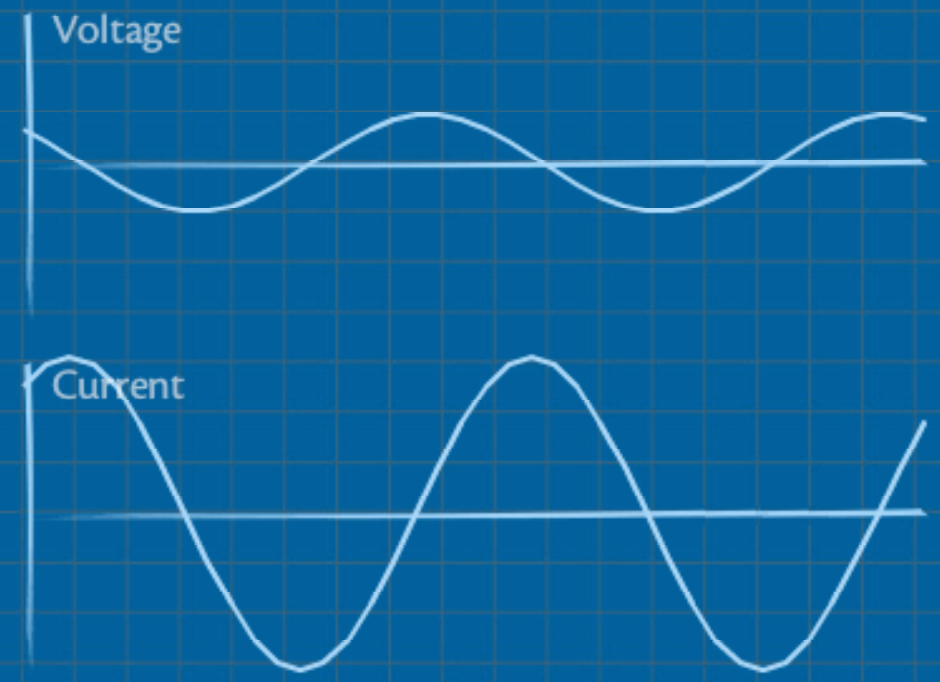

previous

Figure 1

Capacitors and Inductors Module Screen

Proceedings of the 2003 American Society for Engineering Education Annual Conference \& Exposition Copyright (C) 2003, American Society for Engineering Education 


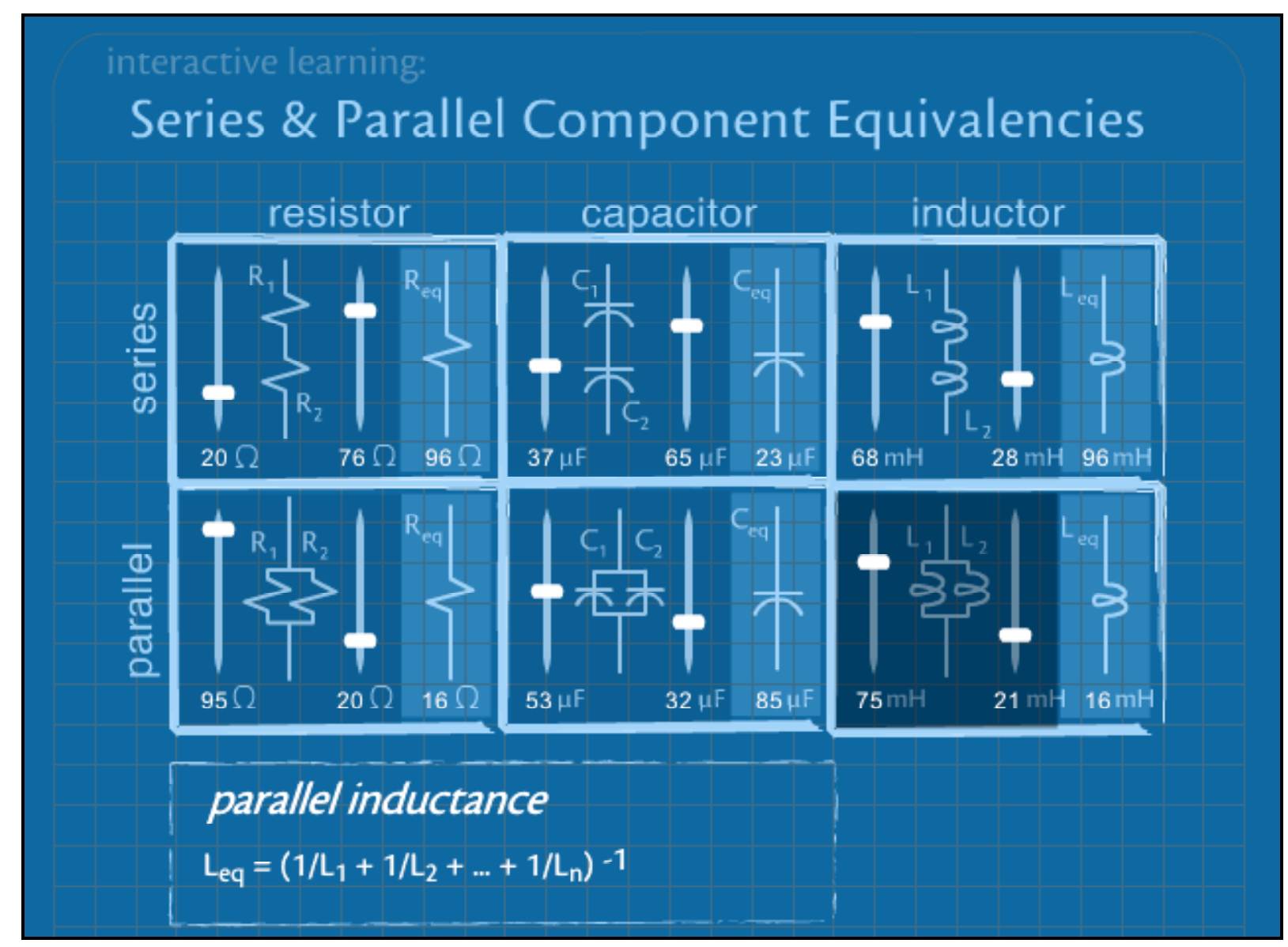

Figure 2

Screen from the Series and Parallel Module

\section{Sample Modules: "Filters and Op-Amps CAD”}

The "Filters" module offers the capability for designing and testing a variety of single and higher order filters along with a means to allow the user to watch and listen to the output resulting from their circuit's effect on a chosen input signal. The current implementation (shown in figure 3) allows a user to design and investigate (up to fourth order) low-pass, high-pass, and band-pass passive circuits, in which the transfer functions and time domain responses can be viewed simultaneously. The filter simulation engine was also used to produce a collaborative problem session experience for the WebTeam development effort. An operational amplifier (OpAmp) module (shown in figure 4) was developed to offer students the opportunity to create and test a variety of circuit configurations. Basic inverting, non-inverting, differential amplifier, integrator, differentiator and comparator circuits are available in either preset or "build your own" configurations. The user can choose the level and frequency of the input signal(s) along with the power supply voltages (+Vcc and $-\mathrm{Vcc}$ ) to explore both the ideal and real characteristics of the device. 


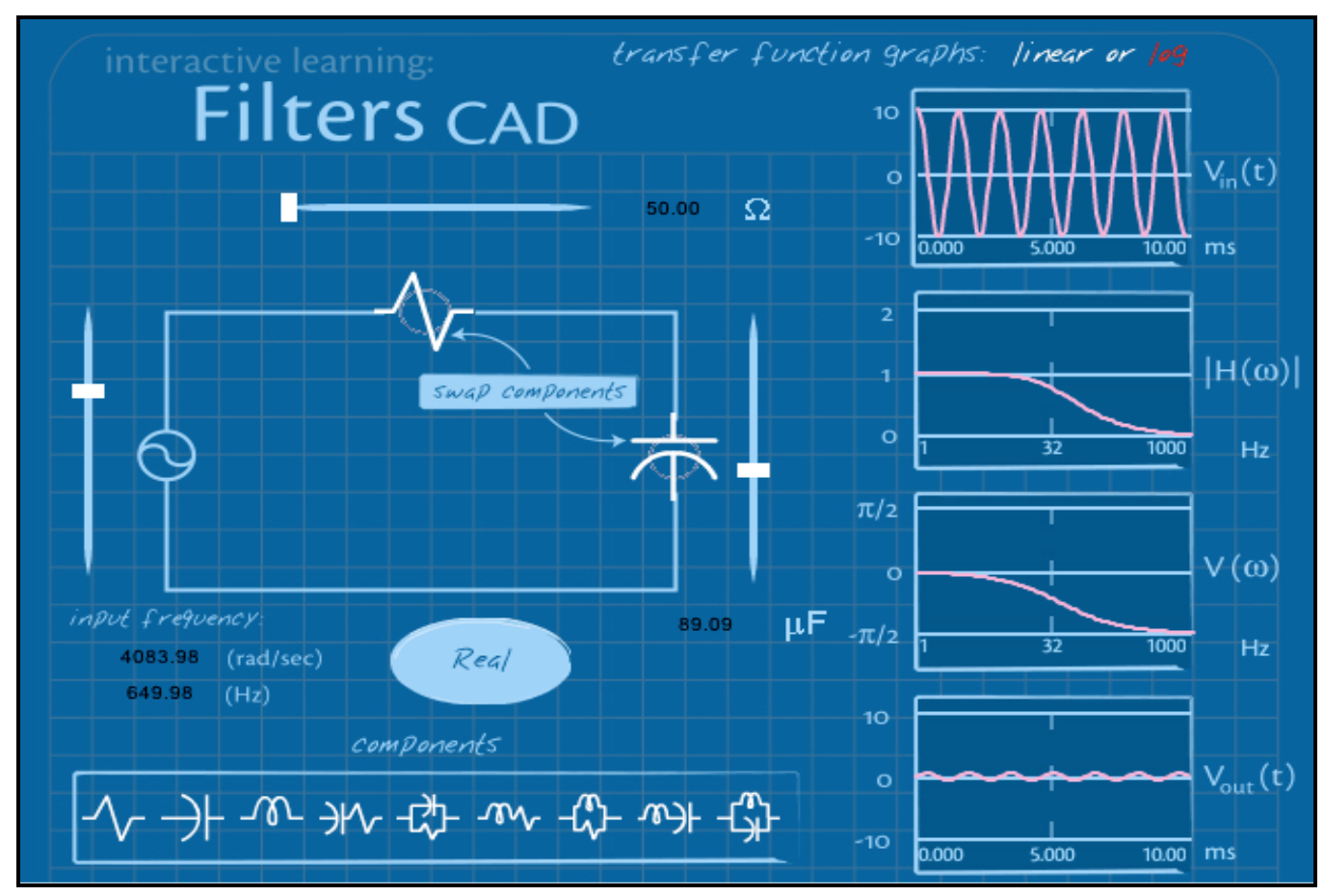

Figure 3

Screen from the Filters CAD Module

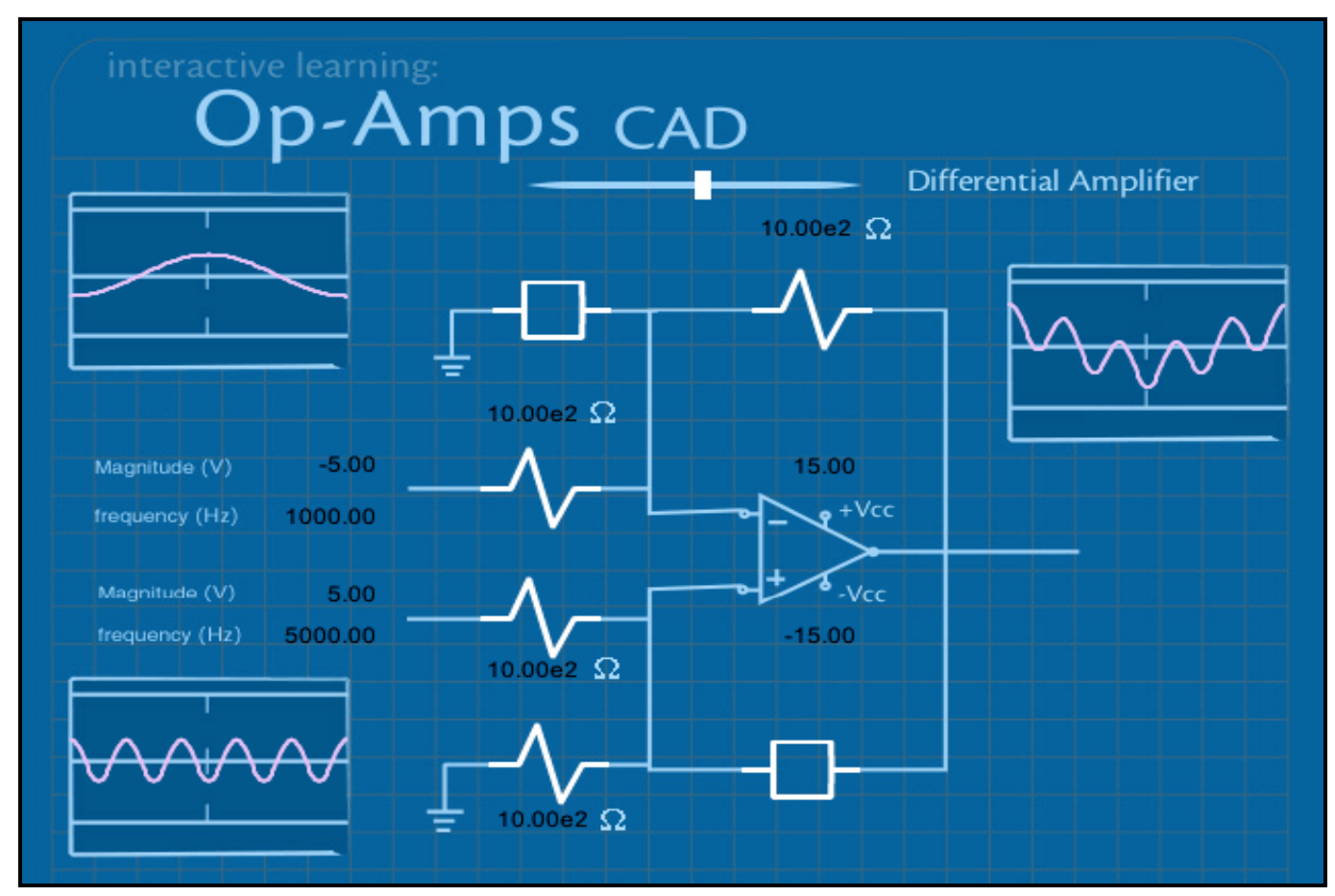

Figure 4

Screen from the Op-Amps CAD Module

Proceedings of the 2003 American Society for Engineering Education Annual Conference \& Exposition Copyright (C) 2003, American Society for Engineering Education 


\section{Educational Multimedia Technologies: Scribe, WebTeam and LongLab}

Scribe provides a means to record and playback a user's interaction with an interactive learning module (in a VCR-like environment - "Bard" - exhibited in Figure 5). Scribe automatically records all of the events (e.g. mouse, keyboard, etc.) that are generated by a user who has accessed a module. It operates in the background; while the recorded data is time stamped and can be further processed (as one could with any signal) for detection of single events, patterns and statistical comparisons.

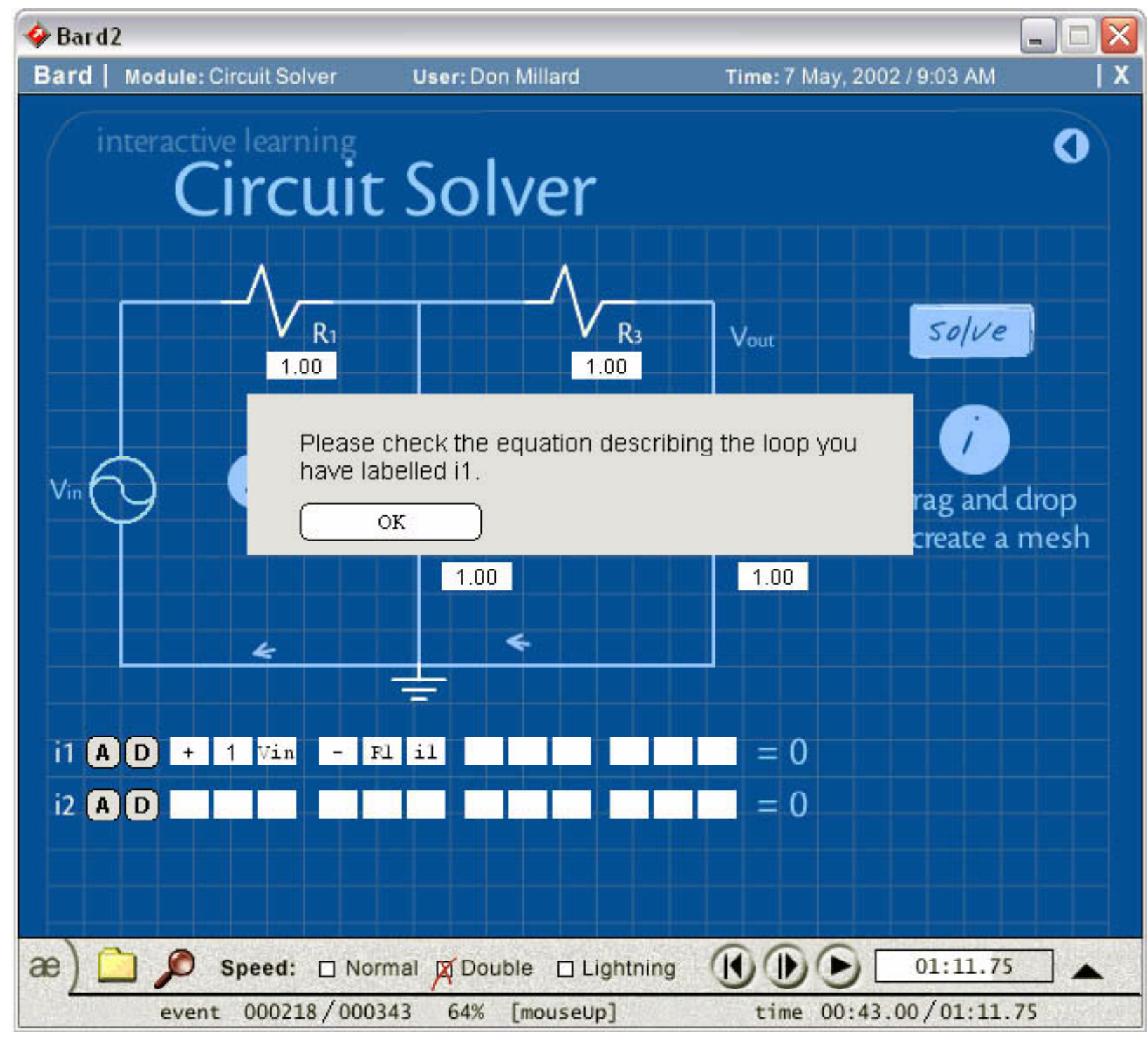

Figure 5

"Scribed" Screen from Circuit Solver Module Being Displayed in Bard Environment 
An instructor or TA can view how an individual student or a collaborating pair of students, use a module and further offer aid while in playback mode. Scribe/Bard can be used by an instructor to accomplish the following:

- Analyze student's difficulties and successes: student's problem solving ability can inferred from their path through the module and their interactions in simulation spaces.

- Gain insight into cognitive processes: A machine can correct homework or a test. Gaining insight into the process by which he/she arrived at the answer provides the opportunity to get at conceptual and procedural misunderstandings.

- Offer directed help: in the form of targeted questions and suggestions. For instance, if the playback shows that a student continually tries to make a circuit "work" by only varying the values of a resistor (instead of changing the type of component), this may show a fundamental misunderstanding of impedance (e.g. resistors, capacitors, or other components of a circuit).

- Differentiate student behaviors: A student who gets a filter to work in a simulated CAD environment by trial and error in a problem-solving task may indicate a lack of basic understanding.

- Evaluate design problems: Scribe offers a way to evaluate a student's work on an openended problem set with more than one possible answer, or an exercise aimed toward design rather than analysis.

WebTeam is a multimedia networking technology that allows easy communication between Interactive Learning Modules (consisting of Director/Shockwave movies) playing on different computers that are connected via the Internet. WebTeam was developed to extend the successful "studio" classroom model of student-to-student cooperation to a distributed, virtual classroom of distance learning students. It is a generic tool that allows a developer to create modules that can be collaboratively used by synchronous student teams to solve problems. The problems are designed such that the actions and results of each component affect the other. Both parts must function individually and in conjunction with the other, forming a broader solution. The students can also communicate directly with each other via a live chat window about the problem at hand —or anything else.

WebTeam brings the collaborative learning component of the interactive learning model to a distributed audience of students. It not only has implications as an enriched means of interactive learning of subject material, but of social interactions across a broader spectrum than is available in any one environment. WebTeam can be used as a means of intervention for an instructor to help a student having difficulty with a problem, locating and clearing up misunderstandings by working together on the actual problem at hand. WebTeam can also be used for setting up mentoring pairings of students.

A band-pass filter problem set (broken into 3 sections) offered a good proof-of-concept for the WebTeam technology. In the first section, one student (e.g. from Rensselaer) designs a lowpass filter while another student (e.g. from UT Dallas) designs a high-pass filter using the Filters CAD module (shown in figure 3). Both students work independently of each other so each student is responsible for his or her own design. The second section combines their designs and has each student responsible for his/her portion of the combined circuit (depicted in figure 6). The low-pass and high-pass filters from the first section are connected in series, demonstrating the 
problems with loading (input and output), thus providing the motivation to investigate the advantages of utilizing an active filter. Each student is allowed to continue to modify their own passive filter, but may not modify the other student's circuit - building teamwork skills. The final section allows the students to cooperatively design an active band-pass filter using the OpAmps CAD module engine. WebTeam offers real-time communication between the student's screens, where they each see instantaneous updates of the other student's actions. Chat windows allow students to further communicate throughout the entire process, encouraging teamwork and giving students the opportunity to "teach" each other.

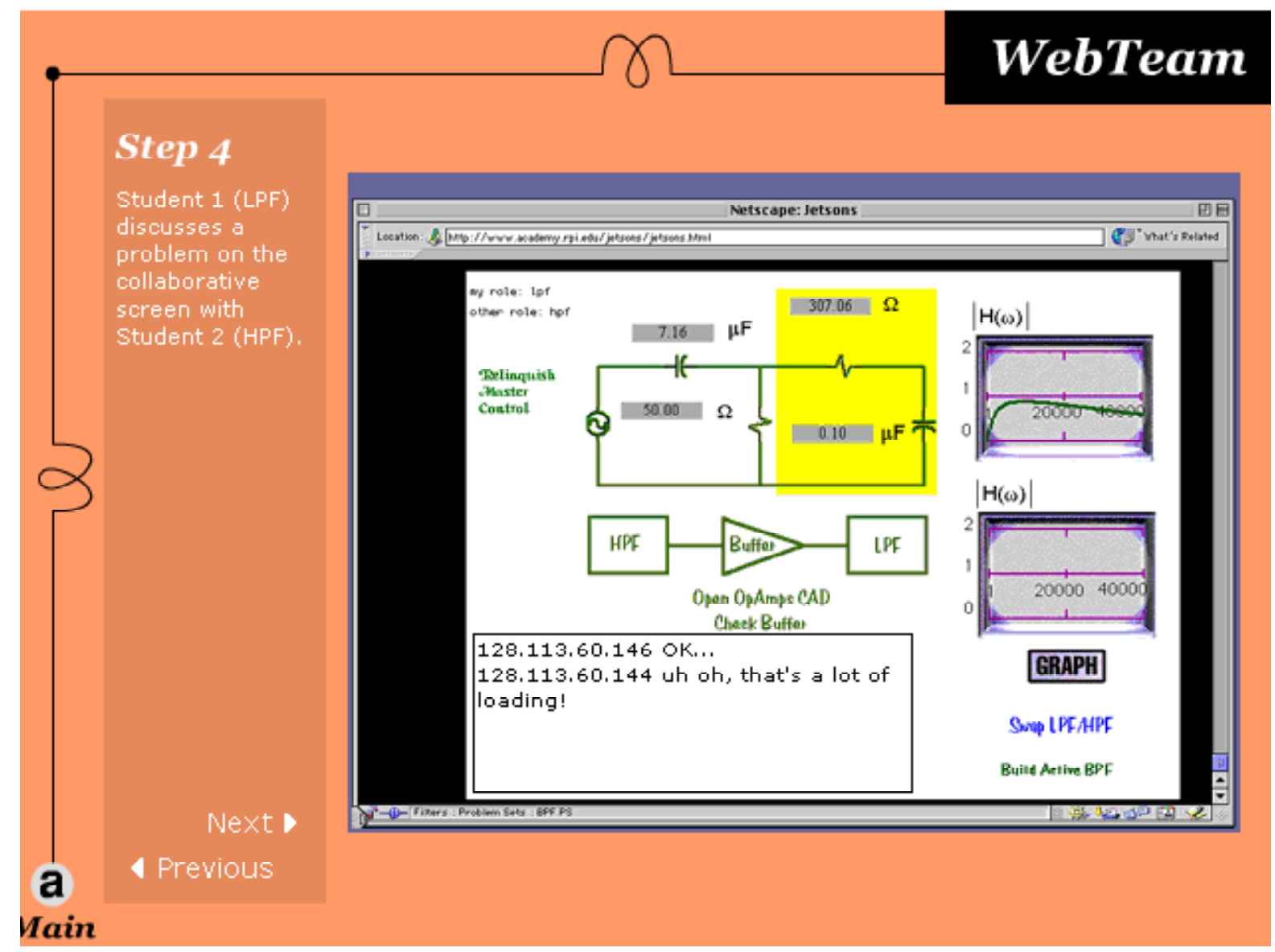

Figure 6: WebTeam Environment Example

LongLab provides Internet access to instrumented experimentation and data gathering using an inexpensive $\mathrm{EZIO}^{\odot}$ microcontroller board to allow for easy control of external hardware through Lingo, the programming language associated with Macromedia's Director ${ }^{\text {TM }}$. It allows users to digitize signals, output PWM waveforms and digitally trigger operations. Students can take remote measurements via the eight $\mathrm{A} / \mathrm{D}$ ports and control remote circuits that are part of courses. LongLab can be used in the design of a wide variety of lab experiments on real-world equipment that are controlled from a distance by way of ILMs, whether through a browser (as a Shockwave ${ }^{\mathrm{TM}}$ application) or as stand-alone compiled application that is downloaded by the student. LongLab creates a means of access to interaction with lab equipment that may be beyond the means of smaller institutions, institutions with fewer resources, or institutions whose main 
focus is not engineering or the sciences.

The investigation of a metal beam that is instrumented with a strain gauge sensor provided the demonstration vehicle for LongLab. An experiment using the beam is performed to provide students with an understanding of the correspondence between second order electrical and mechanical systems. It is designed to have students consider how a pendulum (or a harmonic oscillator) works by exchanging energy (kinetic-potential). Students are asked to determine the beam's effective mass and spring constant using frequency measurements acquired from changes in a strain gauge. The beam also has an inductive coil which generates a signal that is proportional to the velocity of its oscillations. The module gives a remote user the ability to "thwack" an instrumented beam (via the digital I/O ports) and acquire the signal that is detected by the strain gage (via one of the A/D ports). The LongLab implementation also allows the user to remotely "probe" the associated sensing circuitry (Wheatstone bridge, differential amplifier, etc.) as one would in a local setting.

\section{Modules \& Technologies Utilization}

The modules were used at Rensselaer and at the University of Texas at Dallas (UT-Dallas) in lecture and class activities that presented fundamentals and applications of circuit analysis to electrical engineering, computer engineering and telecommunications engineering students. Rensselaer students in Fall 2000, Spring 2001 and Fall 2001 Electric Circuits sections utilized the modules as lecture and supplementary activities that were part of the studio environment. Two specific activities were developed that incorporated the "Circuits Solver" module as a means to introduce students to the application of mesh analysis and Kirchoff's voltage law to solve circuits. In the fall of 2001, electrical network analysis classes at UTD had both EE and Telecommunications Engineering (TE) students who were each surveyed as to the benefit of the modules and technologies. Each semester a teaching assistant was assigned to support the faculty and assist the students in using the ILMs or explaining other concepts.

Two graduate students rewrote the accompanying laboratory manual during the summer of 2001 to insure that the principles exemplified by the modules could be easily integrated into the laboratory sessions. Although Spring 2000 students were introduced to the modules, the first real integration of the ILMs came in the fall of 2000. Students were asked to evaluate the modules and respond to a survey (developed by the Evaluation Consortium of the University at Albany) in the fall of 2000, spring of 2001 and fall of 2001 sections. In addition, students were asked to write a report critiquing the modules and to offer suggestions for future development. The following is a brief description of how a number of the modules were used in the circuits classes at Rensselaer and UT-Dallas:

Simple Resistive Circuits Lecture - The students were shown several examples using the module to illustrate the principles of combining resistances in series and parallel. Students were then given problems to do on their own and provide the answers to the instructor.

Voltage-Divider Circuit Lecture - After explaining the concept and working problems on the board and in the module, students were given problems in class to demonstrate that they had understood the concept. Answers were then verified using the module.

Introduction to Mesh Currents Lecture - Using the circuit diagram in the circuit solver module, various mesh currents were labeled and component values selected. The circuit solver module was then used by the students to find the value of the mesh currents. The students were 
encouraged to use the module on their own computer to help solve the assigned problems. The module was particularly effective because it dynamically showed the direction of current flow in the circuit, thus enabling the student to grasp the concepts faster.

Operational Amplifiers Lecture - The Op-Amp CAD module was used to demonstrate the principals of inverting, non-inverting and difference amplifier. Again, the students were asked to try various configurations on their own as part of their homework.

$A C$ Circuits and $2^{\text {nd }}$ Order Systems Lectures - After introducing the concept of frequency and using the module to visualize the AC system response of various circuits, students used the module to help solve problems. The module was later utilized to provide a sense of how circuits respond to various input signals and help visualize the application of Laplace transforms.

Sinusoidal Steady State Analysis Lecture - The Phasors in Circuit Analysis module was used to show voltage, current and phase angle relationships in simple series RC/RL circuits driven by a sinusoidal input. This was particularly illustrative, since effects on voltage, current and phase angle were viewed in real-time as the circuit parameters were modified (e.g. input signal frequency, etc.) by the instructor.

\section{Evaluation and Assessment Findings}

The viability of the modules as an educational tool was put through many different tests to verify the accuracy of the content, the quality of the prose, the consistency of the presentation and interactivity, and the educational usability. These tests involved in-house review, classroom observations, external peer assessment, and thorough evaluation by educational technology experts. The Evaluation Consortium of the University at Albany created and deployed a formal multi-page questionnaire (for external reviewers) and a system where a student user's progress and responses are videotaped for in-depth analysis. This typically involved a videotape monitor directed at the student while the computer screen images were simultaneously in the camera's field of view. The evaluation of the technologies utilized both video cameras and recorded Scribe files to assess the student learning effects.

The Fall 2001 grade data from a UT-Dallas EE/TE 3301 section clearly illustrates the impact of the CCLI modules. Fourty students were enrolled at census day and seven students dropped or did not take the final exam. Seventeen students received a failing grade on exam one, yet there was only one student who failed the final exam. Since most of the students had no prior background in circuit theory, it is clear that through a combination of effects; tutoring, hard work and the use of the modules, $98 \%$ of the students were successful by the end of the course compared to the $58 \%$ in exam one. This is in stark contrast to prior years, in which a significantly lower percentage of students passed the course. The modules filled a critical gap in the students' education by helping them to gain intuition and confidence and, ultimately, "get it." Furthermore, there was a direct correlation between those who spent a good deal of time working with the modules and improvement in their grades.

The students' response to the use of the modules was very favorable. In particular, the Filters CAD, Op-Amps CAD, Circuit Solver and 2nd Order Systems modules were noted as having significantly improved their understanding. The most popular module was the Circuit Solver, since the dynamic graphics illustrating the assumed direction of current flow helped to turn on the light of understanding. The CCLI modules provide a structured playspace in which

experimentation, the ability to make naïve errors and the ability to ask "what if". Using the CCLI 
modules has provided the faculty with new insight into what students need and don't understand when introduced to a new topic, such as Circuits. We believe that the modules, enhanced with Scribe, could be very effectively used by tutors working with students and plan to distribute them via the IEEE, TSPE and SWE student tutoring groups.

The conclusion drawn by the evaluators was that the development of the modules and technologies proof-of-concept CCLI project conducted at RPI and UT Dallas successfully met its initial goals. ${ }^{11}$ All stakeholders noted a definite need to move the project to the next level by making minor modifications to the software, thus enhancing its capability to capture students' cognitive and affective learning patterns in an electronic format in Scribe. Utilizing the ILMs in the classroom was found to add a higher degree of scaffolding experiences for the studentparticipant. Faculty and students reported that the modules provided alternative methods of instruction necessary to assist them in the visualization of the core concepts and helped them to broaden their generalized problem solving skills. Both also noted signs of improved individual outcomes (e.g. improved scores, grades, etc.) pertaining to learning effect.

The use of Scribe in conjunction with the Circuit Solver module revealed a number of interesting observations that, though to one might seem obvious, are easily overlooked by one who has taught the same class on numerous occasions - particularly in the same sequence. For example: formulating solutions to circuits is typically introduced using nodal analysis, which is based upon Kirchoff's current law. When students are then asked to apply mesh analysis (which is based upon Kirchoff's voltage laws), the "scribed" files clearly showed that they would often first attempt to sum the currents in a loop - rather than the voltages. Therefore, the order in which we present such material needs to be considered in concert with how we later introduce "alternative" methods. We should recognize that the students could have such cognitive impediments resulting from first becoming familiar with prior techniques.

We have simply scratched the surface in understanding how to best utilize these technologies - in particular, the Scribe data. Combining the use of interactive learning modules with the technologies described above offers the ability for us to further customize/optimize a student's education - to best take advantage of her/his particular learning style. We are at the threshold of being able to reap the benefits of how advanced visualization, when coupled with compelling interactivity, can dramatically improve a student's ability to build and retain a deep understanding of science, engineering and mathematics. We desperately need to use such materials and technologies to further stimulate K-12 students - at the point when they are exposed to such topics - to contemplate and pursue technological careers.

\section{Acknowledgement}

The authors gratefully acknowledge the sponsorship of the National Science Foundation. The work described in this paper was funded by a grant from the Department of Undergraduate Education - through the Course, Curriculum and Laboratory Instrumentation (CCLI) Educational Materials Development program (DUE - 9950356).

\section{References}

Proceedings of the 2003 American Society for Engineering Education Annual Conference \& Exposition Copyright (C) 2003, American Society for Engineering Education 
[1] Felder, R., "The Warm Winds of Change." Chem. Engr. Education, 30(1), 34-35, Winter 1996.

[2] D.A. Kolb, Experiential Learning: Experience as the Source of Learning and Development. Englewood Cliffs, NJ, Prentice-Hall, 1984.

[3] R.M. Felder and L.K. Silverman. "Learning Styles and Teaching Styles in Engineering Education." Engr. Education, 78 (7), 674-681, 1988.

[4] M. Kadiyala and B.L. Crynes, "A Review of Literature on Effectiveness of Use of Information Technology in Education,” J. Engr. Education, 89(2), 177-189, 2000.

[5] Millard, D.L., Sanderson, A.C., Jennings, W.J., Wong, A., Patel, A., Brubaker, W., Perala, M., Krawczyk, T., and Slattery, D., "Interactive Learning Modules for Electrical and Computer Engineering, IEEE Frontiers in Education '97 Conference, March 1997.

[6] "Quality of Engineering Education," Final Report of the Quality of Engineering Education Project, American Society for Engineering Education, September 1986.

[7] Millard, D. L., Grab Students' Attention with Multimedia - How to make the most of educational presentation software, ASEE Prism Feature Article, December 1998.

[8] McKenna, A. \& Agogino, A. (1998) A web-based instructional module for teaching middle school students engineering design with simple machines. Paper presented at the annual meeting of the American Educational Research Association, San Diego.

[9] Jacobson, M. J., \& Spiro, R. J. (1994). Hypertext learning environments, cognitive flexibility, and the transfer of complex knowledge: An empirical investigation. Journal of Educational Computing Research, 12(4).

[10] Millard, D. L., Burnham, G., "Innovative Interactive Media for Electrical Engineering Education", IEEE Frontiers in Education '01 Conference, October 2001.

[11] Newman, D., Reinhard, D. Elaine, and Kirk, J., "Development and Implementation of Web-Based Interactive Learning Modules and Educational Technologies - Technical Assistance and Evaluation”, Formative Evaluation Report to NSF, March 2002.

\section{Dr. Don Millard}

Dr. Millard directs the Academy of Electronic Media and is a member of the Electrical, Computer, and Systems Engineering (ECSE) department at Rensselaer. He has authored a variety of multimedia-based lecture resources, and taught courses involving circuits, analog/digital electronics, electronic instrumentation, communication circuits, electronics design and manufacturing, and multimedia programming for more than 20 years.

\section{Dr. Gerald Burnham}

Dr. Burnham is the head of the Electrical Engineering department at UTD and received degrees in mathematics (BA, MS), computer science (MS) and a Ph.D. in EE. Dr. Burnham has served as an ABET program evaluator since 2000, as the Director of the Louis Stokes Alliance for Minority Participation at UTD, and as the activities chairman for the IEEE Dallas Section. 